\title{
Hiring of people with disabilities: Perceptions of Hispanic small business
} \section{owners}

\author{
Roy K. Chen ${ }^{\mathrm{a}, *}$, Charlene J. Blankenship ${ }^{\mathrm{a}}$, Bryan S. Austin ${ }^{\mathrm{b}}$, Vanessa C. Cantu \\ and Wilaiporn Kotbungkair ${ }^{\mathrm{C}}$ \\ ${ }^{a}$ University of Texas Rio Grande Valley, Edinburg, TX, USA \\ ${ }^{\mathrm{b}}$ University of Idaho, Boise, ID, USA \\ ${ }^{\mathrm{c}}$ Thammasat University, Bangkok, Thailand
}

Revised/Accepted April 2015

\begin{abstract}
.
BACKGROUND: Employment of people with disabilities continues to be a concern in the field of rehabilitation counseling. Employment rates remain low, resulting in many people with disabilities living at or below the poverty line.

OBJECTIVE: The purpose of this study was to investigate the perceptions of Hispanic small business owners toward hiring people with disabilities.

METHODS: The 38-item Employer Attitudes Questionnaire (EAQ) and the 33-item Small Business Owners Survey (SBOS) were used to investigate attitudes and concerns about hiring issues along with the business owners' general feelings toward the Americans with Disabilities Act (ADA). Survey packets were distributed in the business districts of two selected cities in southern Texas. Two hundred and seventeen participants took part in the study.

RESULTS: The findings suggest that there is a range of views about the capabilities of workers from various disability categories as well as differing opinions on the cost of reasonable accommodations. The results of a regression analysis yielded three significant predictors influencing hiring decisions: whether the business owner had a family member or a friend with a disability, the business owner's marital status, and their awareness of the ADA.

CONCLUSIONS: There is a continuing need to educate small business owners about disability- and employment-rights legislation; however, cost considerations to provide reasonable accommodations for people with disabilities seem to be significantly more important for small business owners than for large corporations.
\end{abstract}

Keywords: Attitudes, employment, disability, small business owners

\section{Introduction}

Human capital is a nation's most important and valuable asset in sustaining its competitiveness in the increasingly globalized economy. Although neither Singapore nor Hong Kong has any natural resources, these two former British colonies belong to the elite circle of the world's most affluent nations in terms

*Address for correspondence: Roy K. Chen, University of Texas Rio Grande Valley, Edinburg, TX, USA. E-mail: roy.chen@ utrgv.edu. of gross domestic product per capita and living standards (World Trade Organization, 2015). Their success in transforming themselves from backward seaports into major modern hubs for trade, financial services and technology is in part attributed to the foresight of their governments' heavy investment in human capital. Full participation of citizens from diverse backgrounds in the workforce is, therefore, very critical to building a strong economy and a nation's prosperity. Since World War II, the United States has witnessed gradual changes in the demographic composition of its workforce as more women, 
ethnic minorities and new immigrants have entered the job market. However, there is a group of Americans which collectively has had less luck securing gainful employment. According to the U.S. Department of Labor (2011), the unemployment rates for people with and without disabilities are $8.4 \%$ and $14.5 \%$, respectively. On a similar note, Phillips and Stuifbergen (2006) found that $34 \%$ of adults aged 21 to 64 who either had a disability or a limitation had worked the week before. This figure among adults in general was $74 \%$. Needless to say, people with disabilities are very concerned about employmentrelated issues and the challenges they are currently facing (Nary et al., 2004; Wolkstein \& Harding, 2010).

\subsection{The Americans with Disabilities Act of 1990}

The high unemployment rate among people with disabilities is disconcerting considering the passage of the Americans with Disabilities Act (ADA) is over two decades old. Current and past statistics illustrate that people with disabilities are still facing employment barriers despite the disability-rights legislation that was created to promote advancement in this area as well as others (Smith, 2007). Because people with disabilities tend to be more frequently unemployed or underemployed, they often fall below the poverty line (Karger \& Rose, 2010). The authors also found that "the economic hardship experienced by the disabled population is astounding" (p. 77). Chiefly, people with disabilities face further problems due to unemployment because they often lack health insurance, are more often in need of medical and hospital care than those with no disabilities, and spend more of their own finances on medical care than those who are able-bodied (Blanck, 1996; Karger \& Rose, 2010; Karger \& Stoesz, 2009; Kim, 1996).

Bruyère et al. (2010) reiterate that since the passage of the ADA in 1990, employment and economic disparities have continued for people with disabilities. Kennedy and Olney (2001) state that the ADA's purpose was to help with employment, job retention and promotion in the work setting for people with disabilities-in other words, to protect them from work discrimination. However, these authors question the efficacy of this legislation. They emphasize that despite the passage of the ADA, people with disabilities still have the worst (i.e., lowest) employment rate of any group in the U.S. Moreover, people with disabilities who reported job discrimination tended to be younger, poorer, and had more severe disabili- ties than those who did not report (Kennedy \& Olney, 2001).

Even though the ADA was considered a landmark in civil rights legislation, Title I has presented challenges (Mitchell, Alliger, \& Morfopoulos, 1997; Wolkstein \& Harding, 2010). Title I specifically deals with the employment of people with disabilities, stating that people with disabilities cannot be denied a job simply because of their health status (Kennedy \& Olney, 2001). It also requires that employers provide "reasonable accommodations" for employees with disabilities. However, these accommodations must not place an "undue hardship" on, or threaten the health or safety of, others (Karger \& Rose, 2010, p. 74-75). 'Reasonable' can be interpreted as meaning anything that does not place a burden on the employer, while 'accommodations' refer to the actual arrangements put into place (Pigini et al., 2010).

\subsection{The Rehabilitation Act of 1973}

The Rehabilitation Act of 1973, like the ADA, prohibited job discrimination (Sherr \& Babovich, 1997). However, the major difference between the two legislations was that the ADA expanded the coverage from public entities to private ones (e.g., federal government to private companies); the operational definitions of disability and other related terms remained the same in both bills (Valderrama, 2010). More specifically, it was Section 503 of the Rehabilitation Act that required federal contractors to hire and promote people with disabilities (Maffeo, 1990). At the time this legislation (Rehab Act) was introduced, individuals with disabilities were referred to as handicapped instead of using the person-first language most acceptable today (Akabas, 1976). Akabas (1976) also referred to the Rehab Act as one of affirmative action-in that it promoted assistance for a particular group - people with disabilities.

\subsection{Negative attitudes}

Still, before an employee with a disability can even request accommodations, a major hurdle that must be overcome is the attitudes of others, specifically the attitudes of employers. Shannon, Schoen, and Tansey (2009) explain that negative attitudes toward people with disabilities are a major problem in our society. In fact, one of the main reasons for the ADA's creation was to address attitudes toward people with disabilities and how they help to shape society's perspectives (Douglas, 1992). Attitudes are defined 
as the unfavorable or favorable predisposition one holds when assessing a person, object, or idea (Eagly $\&$ Chaiken, 2007). They have three components: behavioral (actions), affective (feelings), and cognitive (thoughts) (Altmann, 2008; Eagly \& Chaiken, 2007). Attitudes can be learned from close people in one's life, such as family and teachers. However, they are also shaped by what the media transmits through television, movies, songs, and the Internet. Many people lack awareness of certain disabilities, because the media may be their only source of information. It is therefore important for advocates to voice their concerns when the information that is presented is incorrect (Mancuso, 1990). According to Rillotta and Nettlebeck (2007), since attitudes are learned, they can also be changed. In short, with increased knowledge, one's predisposition can be altered because attitudes are not static.

However, if an employer has a negative attitude toward people with disabilities, then it will be very difficult to even get one's foot in the door, let alone secure a job. In essence, an owner's attitude can determine whether or not an individual gets work (Kennedy \& Olney, 2001). Education and knowledge are huge factors to consider when taking employers' attitudes into account. Professionals in the field, such as vocational rehabilitation counselors and those in other similar professions, can educate employers, especially by reinforcing the fact that people with disabilities are actually very capable of completing tasks, and in some instances, are even better at them than the general population (Maloney, 1976). Also, these professionals should be encouraged to inform employers about the reasonable accommodations that can be introduced into the work environment to make the workers' transition flow smoothly (Maloney, 1976; Mancuso, 1990).

Another consideration suggested by Magura (2007) is for the job applicant, or the employee who has already obtained a position, to educate the employer on their disability as well as on the reasonable accommodations that can be used. The employee can also direct the employer to the Job Accommodation Network (JAN) website, a federal resource that describes multiple disabilities as well as helpful work accommodations (Magura, 2007). Along the same lines, Mancuso (1990) suggests that advocates and/or rehabilitation professionals need to educate people with disabilities about the laws (e.g., ADA) that protect their rights. They should also encourage them to become part of an organization or association that promotes education and awareness concerning disabilities, laws, and more specifically, employment laws.

Companies that embrace a diverse group of employees tend to fare better in the economic world (Ball et al., 2005; Ramirez, 2000). Diversity does not just refer to race, ethnicity, or gender; it also applies to hiring people with disabilities. Ball et al. (2005) conducted an examination of Fortune Magazine's 2003 top 100 companies' diversity policies. Almost half of these companies (42\%) include people with disabilities in their definition of a diverse work setting. In addition, Ball et al. (2005) analyzed these companies by observing their recruiting activities, initiatives, events, and information publicly available on their official websites. The authors then broke down the companies by industry and divided the companies into the categories of inclusive, noncommittal, and disability absent umbrella. Inclusive companies expressly included individuals with disabilities in their diversity policies. Non-committal companies did not expressively mention people with disabilities in their policies. Disability absent companies did not mention people with disabilities at all.

Ball and colleagues (2005) examined 10 major industries (e.g., financial, technology, health, retail, communications/media, chemical, oil/energy, consumer products/services, industrial products/services, and insurance). The inclusive companies included Bank of America, Dell, Target, Sysco, and Allstate. The non-committal companies included Fannie Mae, Wal-Mart, Sprint, Walt Disney, UPS, and State Farm. The disability absent companies included Merrill Lynch, Safeway, Motorola, Coca Cola, and General Motors. While the majority of the Fortune 100 companies are not considered small businesses because they do not have less than 100 or even less than 500 employees, it is still relevant to recognize that the majority of these companies have a diversity policy in place that specifically includes employees with disabilities. They serve as models to their smaller counterparts in showing that embracing employees from different populations can actually make a business more competitive.

Although there is no one type of small business that is unwillingness to hire people with disabilities, employers' hiring decisions are nevertheless often influenced by the types of and severity of disabilities (Huang \& Chen, 2015). For instance, people with visual impairments have trouble maintaining, seeking, or even obtaining a job (Unger, Rumrill, \& Hennessey, 2005). In fact, Unger et al. (2005) 
report that people with visual impairments had much trouble getting hired than people with less noticeable disabilities. This claim is supported by Pranshke and Wright's study (1995), which found that onefifth of small businesses employed people who had human immunodeficiency virus (HIV) or acquired immunodeficiency syndrome (AIDS). Burns, Young, and Maniss (2007) found that Hispanics the fastest growing minority group, faced an excessively high rate of diagnosis of both HIV and AIDS compared to other minority groups; this diagnosis affects their employment status. Other physical conditions that result in a low rate of employment for people living with them include diabetes, cancer, stroke, and cardiovascular problems (Smith, 2007). The author stated that the one reason for these low employment rates might be the individual's inability to physically care for themselves. People with mental disabilities (e.g., depression and anxiety) also face challenges finding employment. Smith (2007) found that people with paranoid delusional disorder, major depression, bipolar disorder, and schizophrenia have difficulty obtaining and maintaining employment. Vaughn and Boston (2010) found that "women of color" (Latinas, African Americans, American Indians, and Asian Americans) with psychiatric disabilities have particular difficulty getting work.

Work does not just fulfill the financial aspect of one's life, it is a positive emotional motivator as well (Akabas \& Gates, 2000). Like the other researchers, these authors mention the importance of having policies that address employees with disabilities, of obeying the ADA requirements, and establishing reasonable accommodations (e.g., support from colleagues and supervisor). Another less visible disability is people with substance abuse issues (e.g., alcohol and drugs). While some employees might exhibit symptoms that disrupt work (e.g., repeatedly absent from work), others may not (Bennett et al., 2006). Again, small businesses should have policies in place that discuss this issue and should maintain open communication between employer and employee if an issue is suspected (Bennett et al., 2006).

Our study narrows its scope by exploring small business owners' willingness to hire people with disabilities, along with employers' attitudes concerning these kinds of individuals. First, it is important to answer the question, "What constitutes a small business?" A small business is one that is comprised of less than 100 employees, which accounts for the majority of business in the U.S. (Brosseau \& Li, 2000). Another source states that small businesses have less than 500 employees, and that they are quickly growing (Bruyère, Erickson, \& VanLooy, 2006). And although the ADA covers owners who have 15 or more employees, reasonable accommodations can also be put into place if requested by the worker with a disability who works at a much smaller business (Magura, 2007). The aim of the present study was to examine the attitudes of Hispanic small business owners toward hiring of people with disabilities and to explore factors that influence their hiring decisions. Two research questions guided the study: (1) What are the perceptions of business owners toward hiring people with disabilities? and, (2) What factors influence business owners' decisions toward hiring people with disabilities?

\section{Method}

\subsection{Participants}

Two hundred and seventeen Hispanic small business owners in southern Texas were recruited for the study. The average age of the participants was 37.77 years old $(S D=12.28)$. Only $8.8 \%$ of the business owners indicated that they had a disability, but $70.0 \%$ of them revealed that they had a family member, friend, or relative with a disability. Sole proprietorship (45.2\%) accounted for the largest choice of company type, followed by corporation $(22.6 \%)$, partnership $(21.7 \%)$, and others (10.6\%). Retail/wholesale (43.3\%) was the most common business sector, followed by other business sector (23.5\%), services/transportation (20.7\%), and professional/engineering/finance (12.4\%). The majority of the companies $(55.3 \%)$ had five or fewer employees. The educational attainment of the participants was most likely to be less than a bachelor's degree (71.0\%) with $29.0 \%$ having obtained a bachelor's degree. More than half of the business owners were female (52.5\%), and most $(59.4 \%)$ were currently married. The participants were approximately evenly split between first or second generation Americans (49.8\%) and third or higher generation Americans (50.2\%). Over threequarters of the participants $(77.4 \%)$ were aware of the ADA, but most (65.9\%) did not currently have any employees with disabilities.

\subsection{Instruments}

Employer attitudes toward the hiring of people with disabilities were measured by summation of 
the 38 items on the Employer Attitudes Questionnaire (EAQ; Diksa \& Rogers, 1996), using a Likert scale from $1=$ not a concern, $2=$ minimal concern, $3=$ moderate concern, $4=$ considerable concern, to $5=$ great concern . Higher scores reflected greater reluctance on the part of a business owner to hire people with disabilities. The Cronbach's alpha for the current study was 0.965 .

The first two authors developed a 33-item Small Business Owners Survey (SBOS; 2010) to inspect small business owners' concerns about issues of hiring individuals with disabilities and their general feelings toward the ADA. The first 11 items of the SBOS inquired about a participant's general demographic information, such as age, marital status, level of education, sex, primary language spoken at home, and disability status. The next 10 items asked about the characteristics of the business entity, for example, business type, company size, years since established, and awareness about the ADA. More specifically, participants were to indicate their perceived reasonable cost(s) of accommodation incurred for hiring an employee with a disability and the amount of federal tax incentive credits necessary to encourage them to create a barrier-free work environment. Items \#22 to \#36 asked what type of disability would be of greatest concern to an employer when hiring a new employee and what work-related responsibility he or she would be most and least willing to delegate to an employee with a certain type of disability (i.e., hearing impairment, visual impairment, speech impairment, mobility disability, psychiatric disability, developmental disability, and HIV/AIDS).

\subsection{Procedure}

The study was conducted over a period of six weeks in business districts of two selected cities in a southern Texas county. Survey packets, available in both English and Spanish languages, were distributed to participants who agreed to take part in the study.

\subsection{Data analysis}

Preliminary analyses were performed to determine whether demographic and background characteristics of participants differed between those completing the English-language version of the survey differed from those completing the Spanish-language version of the survey. This consisted of chi-square tests for the categorical demographic and background variables and an independent samples $t$ test for the continuous inde- pendent variable (age). The purpose of comparing the demographic and background characteristics and the EAQ scores between those completing the English and Spanish language versions of the survey was to determine if the survey language would be required as a control variable in the main analyses. To answer the first research question, descriptive statistics were examined for the survey items related to the hiring of individuals with disabilities and the items from the EAQ. A multiple regression analysis was performed for the second research question, with the EAQ scale scores as the dependent variables and the independent variables listed above included as predictor variables.

\section{Results}

Chi-square tests and an independent samples $t$ test were performed to compare the demographic and background characteristics of those participants who completed the English language and Spanish language versions of the survey. There was no statistically significant difference between the two groups in terms of whether or not the employer had a disability $\left[\chi^{2}(1)=0.18, p=0.671\right]$, whether or not the employer had a family member, friend, or relative with a disability $\left[\chi^{2}(1)=0.06\right.$, $p=0.810]$, business type $\left[\chi^{2}(3)=6.17, p=0.103\right]$, business sector $\left[\chi^{2}(3)=4.43, p=0.218\right]$, employer educational attainment $\left[\chi^{2}(1)=0.00, p=0.990\right]$, $\operatorname{sex}\left[\chi^{2}(1)=0.14, p=0.711\right]$, awareness of ADA $\left[\chi^{2}(1)=3.56, p=0.059\right]$, or age $[t(208)=-0.64$, $p=0.521]$.

The first research question of this study was: What are the perceptions of business owners toward hiring people with disabilities? When asked about the dollar value for a reasonable accommodation for an employee with a disability, the participants tended to feel that less than $\$ 250$ (31.3\%), between $\$ 250$ and $\$ 500(23.0 \%)$ and between $\$ 500$ and $\$ 1,000$ $(17.5 \%)$ were reasonable values, with fewer respondents $(18.9 \%)$ feeling that an amount over $\$ 1,000$ would be reasonable. The participants felt that federal tax incentives would slightly increase the amount that they would be willing to spend, with slightly smaller percentages of participants indicating that they would spend less than $\$ 250$ (22.6\%), between $\$ 250$ and $\$ 500$ (22.6\%), and between $\$ 500$ and $\$ 1,000$, and slightly higher percentages of participants $(24.4 \%)$ indicating that they would be willing to spend more than $\$ 1,000$. Very few of the participants $(8.8 \%)$ indicated that they had used any job placement service 
Table 1

Employers' preferences of work responsibilities by disability type

\begin{tabular}{|c|c|c|}
\hline Disability Type & Most Preferred $(n)$ & Least Preferred $(n)$ \\
\hline Visual Impairment & - Providing direct services to clients $(n=79)$ & - Filing letters and documents $(n=51)$ \\
\hline Hearing Impairment & - Filing letters and documents $(n=51)$ & - Providing direct services to clients $(n=119)$ \\
\hline Speech Impairment & - Analyzing and synthesizing information and data $(n=47)$ & - Providing direct services to clients $(n=139)$ \\
\hline Mobility Disability & - Providing direct services to clients $(n=64)$ & - Working on a production line $(n=66)$ \\
\hline Psychiatric Disability & - Filing letters and documents $(n=75)$ & - Providing direct services to clients $(n=110)$ \\
\hline Intellectual Disability & - Filing letters and documents $(n=77)$ & - Providing direct services to clients $(n=83)$ \\
\hline HIV/AIDS & - Providing direct services to clients $(n=57)$ & - Providing direct services to clients $(n=93)$ \\
\hline
\end{tabular}

from the Texas Department of Assistive and Rehabilitative Services (DARS) to recruit employees with disabilities.

The next set of questions examined the types of disabilities that the participants would be most willing to hire, and to perform which types of work activities. Table 1 shows employers' preferences of work responsibilities by disability type. Overall, the participants stated that they would be most concerned in hiring someone with a visual impairment (39.6\%), followed by an individual with a psychiatric disability $(16.6 \%)$, and would be least concerned in hiring an individual with a hearing impairment $(5.1 \%)$, followed by speech impairments (6.5\%), developmental disabilities (7.8\%), and HIV/AIDS (8.8\%).

The participants felt that they would be most willing to delegate direct client service responsibilities to an individual with a visual impairment (36.4\%), and least likely to delegate filing letters and documents (23.5\%) to such an individual. For individuals with hearing impairments, the participants stated that they would be most likely to delegate filing letters and document responsibilities (23.5\%), and least likely to have this person provide direct services to clients $(54.8 \%)$. The participants felt that they would be most likely to delegate responsibilities related to analyzing and synthesizing information (21.7\%), and filing letters and document responsibilities $(21.2 \%)$ to a person with a speech impairment, and least likely to delegate direct client services (64.1\%).

For individuals with a mobility disability, the participants would be most likely to delegate the provision of direct client services (29.5\%) and least likely to have this person work on a production line (30.4\%). For potential employees with psychiatric disabilities, the participants would be most likely to delegate the filing of letters and documents (34.6\%) and least likely to have this person provide direct services to clients $(50.7 \%)$. The participants felt that individuals with developmental disabilities would be most able to file letters and documents (35.5\%) and least likely to provide direct services to clients $(38.5 \%)$. Finally, when the disabled person had HIV/AIDS, the participants felt that they would be best suited to providing direct services to clients (26.3\%), but others felt that such an individual would be least well-suited to this task (42.9\%).

The second research question of this study was: What factors influence business owners' decisions toward hiring people with disabilities? The results of the regression analysis are displayed Table 2. Overall, the regression model was statistically significant, $R^{2}=0.13$, Adjusted $R^{2}=0.05, F(16,193)=1.74$, $p=0.041$. Although the $R^{2}$ for the model was small, it still could provide useful information to explain the attitudes of small business owners. Three of the predictor variables were statistically significant. Having a family member, friend, or relative with a disability was associated with increased concern about hiring an individual with a disability $(\beta=0.17, p=0.017)$. Marital status was also statistically significant $(\beta=-0.19$, $p=0.012$ ), indicating that married individuals had fewer concerns about hiring an individual with a disability. Awareness of ADA was the third statistically significant predictor variable $(\beta=0.14, p=0.048)$, indicating that those participants who were aware of ADA tended to have more concerns about hiring an individual with a disability.

\section{Discussion}

Despite the passage of the Rehabilitation Act and the ADA (and their amendments) and the general improvement of employers' attitudes toward the hiring of people with disabilities (Hernandez et al., 2000; Ju, Roberts, \& Zhang, 2013), work-related barriers for United States citizens with disabilities persist. Employment rates and pay continue to be significantly lower for people with disabilities compared to the general workforce (Barrington, Bruyère, \& Waelder, 2014; Ozawa \& Yeo, 2006). One of the reasons for this discrepancy is the fact that many employers still make assumptions or have miscon- 
Table 2

Results of regression analysis with EAQ as the dependent variable

\begin{tabular}{|c|c|c|c|c|c|}
\hline & $B$ & $S E_{B}$ & $\beta$ & $t$ & $p$ \\
\hline (Constant) & 3.29 & 0.25 & & 12.92 & 0.000 \\
\hline Language version (Spanish) & 0.12 & 0.15 & 0.06 & 0.81 & 0.418 \\
\hline Personal disability (yes) & -0.27 & 0.19 & -0.10 & -1.40 & 0.163 \\
\hline Family/Friend/Relative disability & 0.27 & 0.11 & 0.17 & 2.42 & 0.017 \\
\hline Company type (partnership) & -0.03 & 0.13 & -0.02 & -0.26 & 0.795 \\
\hline Company type (corporation) & -0.06 & 0.13 & -0.03 & -0.42 & 0.672 \\
\hline Sector type (retail/wholesale) & 0.14 & 0.13 & 0.10 & 1.07 & 0.284 \\
\hline Sector type (professional/engineering/ financial) & 0.01 & 0.18 & 0.01 & 0.08 & 0.938 \\
\hline Sector type (services/transportation) & 0.03 & 0.16 & 0.02 & 0.22 & 0.828 \\
\hline Company size (more than 5 employees) & -0.09 & 0.11 & -0.06 & -0.87 & 0.386 \\
\hline Education (bachelor's degree) & -0.22 & 0.11 & -0.14 & -1.90 & 0.059 \\
\hline Sex (female) & 0.13 & 0.10 & 0.09 & 1.32 & 0.188 \\
\hline Marital status (married) & -0.28 & 0.11 & -0.19 & -2.55 & 0.012 \\
\hline Generation (3rd or more) & -0.04 & 0.11 & -0.03 & -0.38 & 0.701 \\
\hline ADA awareness (yes) & 0.25 & 0.13 & 0.14 & 1.99 & 0.048 \\
\hline Disabled employees (yes) & -0.04 & 0.12 & -0.02 & -0.31 & 0.760 \\
\hline Age & 0.01 & 0.00 & 0.13 & 1.64 & 0.103 \\
\hline
\end{tabular}

Note. Model $R^{2}=0.13$, Adjusted $R^{2}=0.05, F(16,193)=1.74, p=0.041$.

ceptions about job applicants with certain disabilities (Unger, 2002). Negative employer attitudes about disability type and severity (e.g., intellectual disabilities, psychiatric disabilities), job skills (e.g., productivity, safety, interpersonal skills), employability (e.g., attendance, appearance), and job accommodations (e.g., costs and legal issues) have consistently been noted in the research (Ju et al., 2013; von Schrader, $\mathrm{Xu}, \&$ Bruyère, 2014). Consequently, many people with disabilities in the current economy continue to be perceived as less capable and as financial burdens or liabilities, and therefore, must overcome significant obstacles each day to secure quality jobs, careers, and lives of self-sufficiency.

Data from this study suggest that differential attitudes toward disability exist among Hispanic small business owners. In particular, findings show a variation of beliefs about what is considered "reasonable" in terms of costs for hiring a person with a disability and that knowledge of disability-related federal tax work incentives (e.g., Work Opportunity Tax Credit) only slightly increased the amount they would spend on accommodations. The amounts that business owners considered reasonable ranged from spending more than $\$ 1,000$ to less than $\$ 250$; the lower the costs, the larger the proportion of business owners who viewed amount of spending as reasonable. This finding corroborates a study by Graffam et al. (2002) that found cost considerations to be significantly more important for small business owners (less than 10 employees). The smallness of most of the businesses sampled in this study (i.e., more than half [55.3\%] had 5 or fewer employees) may explain the saliency of costs (e.g., increased supervision and training, workplace modifications) and the need felt by the owners to keep costs to a minimum. Such small business owners may also assign greater importance to how the hiring of a person with a disability will affect co-workers or work unit productivity as a whole (Graffam et al., 2002). Moreover, small business owners in this study may have only limited experience with the use of federal tax work incentives, and therefore, these may go untapped (Koch et al., 2003).

The data, which indicate that most Hispanic small business owners (91.2\%) had not worked with a local state Vocational Rehabilitation (VR) agency (i.e., DARS) supports prior research that has showed employers to have limited contact with VR agencies (Gilbride et al., 2000; Koch et al., 2003). As such, it may be that many Hispanic small business owners do not know that VR services exist, are unclear about what services they can offer, or are uncomfortable using government assistance to support the hiring of employees with disabilities (Gilbride et al., 2000; Koch et al., 2003).

This study's findings also suggest that Hispanic small business owners hold varying opinions about the capabilities of potential workers from various disability categories (e.g., hearing impairment, blindness or visual impairment), many of which seem to confirm stereotypical beliefs. For instance, participants were most willing to delegate tasks that involve direct customer services to workers who are blind or have visual impairments and, are least willing to give this same disability group filing tasks. In another 
example, sample participants were most willing to delegate tasks of filing documents to workers with psychiatric disabilities (e.g., people with mental illness) and, least willing to delegate direct customer service tasks to these same workers. Combined, these findings may suggest that Hispanic small business owners are correct in some of their appraisals of what people with certain disabilities can or cannot do (Gilbride et al., 2000) but that they lack knowledge about the effective job accommodations (e.g., Braille, assistive technology, on-the-job supports) proven to remedy disability-related barriers for many employees with disabilities (Hernandez et al., 2000; McDonnall, O'Mally, \& Crudden, 2014).

Participants were least concerned about hiring workers with hearing and speech impairments, and HIV/AIDS. This confirms earlier research that has shown employers to view workers with sensory or physical disabilities more positively than those with emotional disabilities (Gouvier, Sytsma-Jordan, \& Mayville, 2003; Hernandez et al., 2000; Ju et al., 2013; Unger, 2002). The mixed response in regard to willingness to delegate direct customer services tasks to workers with HIV/AIDS (i.e., 26.3\% were most willing; $42.9 \%$ least willing) may indicate that negative attitudes are present for many Hispanic small business owners toward persons with HIV/AIDS (e.g., business owners' beliefs that workers with HIV/AIDS require increased social distance from customers). This finding concurs with the employer attitude research that found negative attitudes toward people with HIV/AIDS to be evident across cultures (Rao, Angell, Lam, \& Corrigan, 2008).

It is important to note that the results showing Hispanic small business owners to be minimally concerned (only $7.8 \%$ ) with hiring workers with intellectual/developmental disabilities is incongruent with preceding research (Gouvier et al., 2003; Hernandez et al., 2000; Ju et al., 2013; Unger, 2002). This alternative finding may be explained by Gouvier et al.'s (2003) research, which found that employers value workers with intellectual/developmental disabilities, compared to workers with other types of disabilities, because of their commitment and job performance ratings. Furthermore, many Hispanic small business owners may have had positive experiences with persons with intellectual and developmental disabilities and, thus, are more willing to hire a worker with an intellectual and/or developmental disability (Unger, 2002).

The finding that Hispanic small business owners who have a family member, friend, or relative with a disability or who are married, as significantly related to business owner's concerns about hiring a person with a disability (i.e., more concerned if have a family member or friend with a disability, and less concerned if married), may be understood in multiple ways. Family strength and loyalty to family are generally considered to be strongly held values in the Hispanic culture (Graf et al., 2007; Peppas, 2006). From this cultural lens, relations with family or friends may hold greater weight in terms of influencing attitudes toward disabilities for Hispanic small business owners. Consequently, having a close family or friend with a disability may be associated with considerable hardships for many individuals (including small business owners), making it more difficult for Hispanic employers who have such (negative) experiences, to view people with certain types of disabilities as capable of working or of performing specific job tasks (Yuker, 1994). In contrast, perceived economic stability (i.e., both spouses working) may be conceptualized as resulting in greater "family strength" (p. 154) (Graf et al., 2007) which may explain why Hispanic small business owners who were married had fewer concerns about hiring a person with a disability. Furthermore, (married) small business owners may feel that they are in a better position financially to handle any perceived disability-related concerns and costs associated with hiring a person with a disability.

The increased concern indicated by those Hispanic small business owners who were aware of the ADA when deciding to hire a person with a disability corresponds with the research suggesting the ADA is a cause for concern for both employers and workers with disabilities (Dong et al., 2012; Gilbride et al., 2003; von Schrader et al., 2014). It may be that Hispanic small business owners vary in their levels of awareness or factual knowledge of the ADA which can lead to increased reservations or anxiety (Unger, 2002; von Schrader et al., 2014). Concerns about accommodation costs and/or legal consequences may be additional challenges that small business owners face when deciding whether or not to hire a person with disability (von Schrader et al., 2014).

\section{Implications and future research}

In light of the findings for this study of Hispanic small business owners' perceptions toward persons with disabilities, several implications for VR practice and future research can be suggested. 


\subsection{VR practice (Outreach): Building partnerships and employer education}

The value of VR agencies and collaborative work with clients with disabilities and their employers has proven effective for decades in helping people with significant disabilities in attaining their employment goals (Austin \& Lee, 2014; Dutta et al., 2008; Saunders et al., 2006). However, the finding that most Hispanic small business owners in this study did not have any contact (or were not aware of having any contact) with DARS supports accumulating evidence in this area and is a noteworthy concern (Gilbride et al., 2000; Koch et al., 2003). Therefore, VR professionals should make considerable efforts to reach out and establish partnerships with Hispanic employers and small businesses. Such relationships can be structured to be mutually beneficial and to underlie values associated with demand-side models of job placement designed to meet employers' emerging labor market needs (e.g., Gilbride \& Stensrud, 2010). Such outreach should be provided to support and educate employers in developing or enhancing their disability-inclusive employer policies with the intention to build long-term VR agency-small business owner partnerships (Buys \& Rennie, 2001; Erickson et al., 2014).

Participants' attitudes toward disability and inferred importance of ADA awareness and federal tax work incentives in relation to their potential effect on the hiring of persons with disabilities should not be taken lightly. These findings suggest that Hispanic small businesses and related employers may benefit from education that addresses disability awareness (e.g., blindness and visual impairment, psychiatric disabilities, HIV/AIDS), the ADA (i.e., process and information about providing accommodations, latest amendments and case law), and available work incentives (Knapp, Faley, \& Long, 2006; Nazarov \& von Schrader, 2014). These educational efforts can be focused on providing factual information about disabilities, dispelling any practical misinterpretations of the ADA, and publicize effective job accommodations and work incentives when hiring workers with disabilities. Furthermore, since small business owners in this study were most concerned about hiring workers who were either blind or had visual impairments, or had psychiatric disabilities, it is imperative to provide education and information to employers about accommodations such as assistive technology, on-the-job training or work experiences (McDonnall, Crudden, \& Zhou, 2013) and on-the-job supports (e.g., supported employment) (Bond et al., 1997) more often used for these disability groups, respectively.

\subsection{Future employer attitude research}

It is unclear from this study's data how knowledgeable Hispanic small business owners are about the ADA and its application to their business practices. Therefore, surveys and qualitative research of small business owners to ascertain their knowledge, policies, and practices related to the ADA are needed to better understand how Hispanic business owners utilize the ADA. This information can be used to inform educational curricula for small business owners to enhance ADA awareness and associated policy development to promote inclusive workplace practices that value diversity and the hiring of employees with disabilities (Erickson et al., 2014).

Cultural competency research of rehabilitation professionals working for VR agencies, specifically those working with Hispanic small business owners or staff, is needed to identify knowledge, skills, and/or key interpersonal factors linked to enhancing the development of long-lasting VR-business partnerships with Hispanic employers (Glover \& Blankenship, 2007; Graf et al., 2007; Peppas, 2006; Salas-Provance, Erickson, \& Reed, 2002). The importance of VR and their work with Hispanic small business owners provides yet another opportunity to strengthen the value of diversity and expand disability awareness across business and cultural sectors. Therefore, application of essential cultural competencies, if identified, will likely enhance VRHispanic small business owner relationships and lead to improved partnerships (long-term) and outcomes for workers across disability categories (e.g., blindness and visual impairments, psychiatric disabilities, intellectual and developmental disabilities).

Finally, this study's findings of the varying attitudes held by Hispanic small business owners about the hiring of workers based on their disability status suggests a continued need for research to develop knowledge of instructional strategies that have greater potential to change employer attitudes (Hunt \& Hunt, 2004). Such educational intervention (or effectiveness) studies can be developed using a curriculum or fidelity manual informed by findings from the empirical research that highlights demand-side or employer-related factors associated with successful employment outcomes for people with disabilities (e.g., establishment of VR-employer 
partnerships, workplace culture, factual disability information) (Buys \& Rennie, 2001; Chan, Strauser, Gervey, \& Lee, 2010; Gilbride et al., 2003). This research can also link educational interventions to attitudinal changes among employers (e.g., small business owners), and, thus, has the potential to further influence future hiring decisions and job opportunities for workers with disabilities.

\section{Conflict of interest}

The authors have no conflict of interest to report.

\section{References}

Akabas, S. H. (1976). Affirmative action: A tool for linking rehabilitation and the community. Journal of Rehabilitation, 42(3), 20-42.

Akabas, S. H., \& Gates, L. B. (2000). A social work role: Promoting employment equity for people with serious and persistent mental illness. Administration in Social Work, 23(3/4), 163184.

Altmann, T. K. (2008). Attitude: A concept analysis. Nursing Forum, 43(3), 144-150. doi: 10.1111/j.1744-6198.2008. 00106. $\mathrm{x}$

Austin, B. S., \& Lee, C.-L. (2014). A structural equation model of vocational rehabilitation services: Predictors of employment outcomes for clients with intellectual and co-occurring psychiatric disabilities. Journal of Rehabilitation, 80(3), 11-20.

Ball, P., Monaco, G., Schmeling, J., Schartz, H., \& Blanck, P. (2005). Disability as diversity in Fortune 100 companies. Behavioral Sciences and the Law, 23(1), 97-121. doi: $10.1002 / \mathrm{bsl} .629$

Barrington, L., Bruyère, S. M., \& Waelder, M. (2014). Employer practices in improving employment outcomes for people with disabilities: A transdisciplinary and employer-inclusive research approach. Rehabilitation Research, Policy, and Education, 28(4), 208-224.

Bennett, J. B., Patterson, C. R., Wiitala, W. L., \& Woo, A. L. (2006). Social risks for at-risk drinking in young workers: Application of work-life border theory. Journal of Drug Issues, 36(3), 485513.

Bishop, M. (2002). Barriers to employment among people with epilepsy: Report of a focus group. Journal of Vocational Rehabilitation, 17(4), 281-286.

Blanck, P. D. (1996). Empirical study of the ADA (1990-1994). Behavioral Science and the Law, 14(1), 5-27.

Bond, G. R., Drake, R. E., Mueser, K. T., \& Becker, D. R. (1997). An update on supported employment for people with severe mental illness. Psychiatric Services, 48(3), 335-346.

Brosseau, L. M., \& Li, S. Y. (2005). Small business owners' health and safety intentions: A cross-sectional survey. Environmental Health, 4, 23-29. doi: 10.1186/1476-069X-4-23

Bruyère, S. M., Erickson, W. A., \& VanLooy, S. A. (2006). The impact of business size on employer ADA response. Rehabilitation Counseling Bulletin, 49(4), 194-206. doi: 10.1177/0034355206049004010
Bruyère, S. M., von Schrader, S., Coduti, W., \& Bjelland, M (2010). United States employment disability discrimination charges: Implications for disability management practice. International Journal of Disability Management, 5(2), 48-58. doi: 10.1375/jdmr.5.2.48

Burns, S. M., Young, L. R. L., \& Maniss, S. (2007). Factors associated with employment among Latinos living with HIV/AIDS Journal of Rehabilitation, 73(1), 29-37.

Buys, N. J., \& Rennie, J. (2001). Developing relationships between vocational rehabilitation agencies and employers. Rehabilitation Counseling Bulletin, 44(2), 95-103. doi: 10.1177/003435520104400206

Chan, F., Strauser, D., Gervey, R., \& Lee, E.-J. (2010). Introduction to demand-side factors related to employment of people with disabilities. Journal of Occupational Rehabilitation, 20(4), 407-411. doi: 10.1007/s10926-010-9243-7

Diksa, E., \& Rogers, E. S. (1996). Employer concerns about hiring persons with psychiatric disability: Results of the employer attitude questionnaire. Rehabilitation Counseling Bulletin, 40(1), 31-44.

Dong, S., Oire, S. N., Macdonald-Wilson, K. L., \& Fabian, E. (2012). A comparison of perceptions of factors in the job accommodation process among employees with disabilities, employers, and service providers. Rehabilitation Counseling Bulletin, 56(3), 182-189. doi: 10.1177/0034355212468618

Douglas, R. (1992). What a small business needs to know about the Americans with Disabilities Act. American Rehabilitation, 18(4), 35-36.

Dutta, A., Gervey, R., Chan, F., Chou, C.-C, \& Ditchman, N. (2008). Vocational rehabilitation services and employment outcomes for people with disabilities: A United States study. Journal of Occupational Rehabilitation, 18(4), 326-334. doi 10.1007/s10926-008-9154-Z

Eagly, A. H., \& Chaiken, S. (2007). The advantages of an inclusive definition of attitude. Social Cognition, 25(5), 582-602.

Erickson, W. A., von Schrader, S., Bruyère, S. M., VanLooy, S. A., \& Matteson, D. S. (2014). Disability-inclusive employer practices and hiring of individuals with disabilities. Rehabilitation Research, Policy, and Education, 28(4), 309-328.

Gilbride, D., \& Stensrud, R. (2010). Job placement and employer consulting: Services and strategies. In E. M. Szymanski, \& R. M. Parker (Eds.), Work and disability: Contexts, issues, and strategies for enhancing employment outcomes for people with disabilities (3rd ed.) (pp. 325-361). Austin, TX: Pro-Ed, Inc.

Gilbride, D., Stensrud, R., Ehlers, C., Evans, E., \& Peterson, C. (2000). Employers' attitudes toward hiring persons with disabilities and vocational rehabilitation services. Journal of Rehabilitation, 66(4), 17-23.

Gilbride, D., Stensrud, R., Vandergoot, D., \& Golden, K. (2003). Identification of the characteristics of work environments and employers open to hiring and accommodating people with disabilities. Rehabilitation Counseling Bulletin, 46(3), 130-137. doi: 10.1177/00343552030460030101

Glover, N. M., \& Blankenship, C. J. (2007). Mexican and Mexican Americans' beliefs about god in relation to disability. Journal of Rehabilitation, 73(4), 41-50.

Gouvier, W. D., Sytsma-Jordan, S., \& Mayville, S. (2003). Patterns of discrimination in hiring job applicants with disabilities: The role of disability type, job complexity, and public contact. Rehabilitation Psychology, 48(3), 175-181. doi: 10.1037/0090-5550.48.3.175 
Graf, N. M., Blankenship, C. J., Sanchez, G., \& Carlson, R. (2007). Living on the line: Mexican and Mexican American attitudes toward disability. Rehabilitation Counseling Bulletin, 50(3), 153-165. doi: 10.1177/00343552070500030301

Graffam, J., Shinkfield, A., Smith, D., \& Polzin, U. (2002). Factors that influence employer decisions in hiring and retaining an employee with a disability. Journal of Vocational Rehabilitation, 17(3), 175-181.

Hernandez, B., Keys, C., \& Balcazar, F. (2000). Employer attitudes toward workers with disabilities and their ADA employment rights: A literature review. Journal of Rehabilitation, 66(4), 4-16.

Huang, I.-C., \& Chen, R. K. (2015). Employing people with disabilities in the Taiwanese workplace: Employers' perceptions and considerations. Rehabilitation Counseling Bulletin, 59(1), 43-54. doi: 10.1177/0034355214558938

Hunt, C. S., \& Hunt, B. (2004). Changing attitudes toward people with disabilities: Experimenting with an educational intervention. Journal of Managerial Issues, 16(2), 266-280.

Ju, S., Roberts, E., \& Zhang, D. (2013). Employer attitudes toward workers with disabilities: A review of research in the past decade. Journal of Vocational Rehabilitation, 38(2), 113-123. doi: 10.3233/JVR-130625

Karger, H., \& Rose, S. R. (2010). Revisiting the Americans with Disabilities Act after two decades. Journal of Social Work in Disability \& Rehabilitation, 9(2/3), 73-86. doi: 10.1080/1536710X.2010.493468

Karger, H., \& Stoesz, D. (2009). American social welfare policy, (6th ed.). Boston: Allyn \& Bacon.

Kennedy, J., \& Olney, M. (2001). Job discrimination in the postADA era: Estimates from the 1994 and 1995 national health interview surveys. Rehabilitation Counseling Bulletin, 45(1), 24-30. doi: 10.1177/003435520104500103

Kim, P. S. (1996). Disability policy: An analysis of the employment of the people with disabilities in the American federal government. Public Personnel Management, 25(1), 73-88.

Knapp, D. E., Faley, R. H., \& Long, L. K. (2006). The Americans with disabilities act: A review and synthesis of the legal literature with implications for practitioners. Equal Opportunities International, 25(5), 354-372.

Koch, L. C., Rumrill, P. D., Unger, D., \& Kregel, J. (2003). Employers' knowledge and utilization of accommodations. Work, 2l(1), 5-15.

Loo, R. (2002). Attitudes of management undergraduates toward employing persons with disabilities. Journal of Applied Rehabilitation Counseling, 33(2), 24-30.

Maffeo, P. A. (1990). Making non-discriminatory fitness-for-duty decisions about persons with disabilities under the rehabilitation act and the Americans with Disabilities Act. American Journal of Law \& Medicine, 16(3), 279-326.

Magura, C. S. (2007). What are reasonable accommodations and how does a person get them? Inside MS, 25(2), 25-27.

Maloney, S. (1976). Section 503 conference: A new day for handicapped people. Journal of Rehabilitation, 42(3), 14-18.

Mancuso, L. L. (1990). The ADA and employment accommodations: What now? American Rehabilitation, 16(4), 15-17.

McDonnall, M. C., Crudden, A., \& Zhou, L. (2013). Employer attitudes towards persons who are blind or visually impaired: Perspectives and recommendations from vocational rehabilitation personnel. Journal of Rehabilitation, 79(3), 17-24.
McDonnall, M. C., O’Mally, J., \& Crudden, A. (2014). Employer knowledge of and attitudes toward employees who are blind or visually impaired. Journal of Visual Impairment and Blindness, 108(3), 213-225.

Mitchell, K. E., Alliger, G. M., \& Morfopoulos, R. (1997). Toward an ADA-appropriate job analysis. Human Resource Management Review, 7(1), 5-26.

Nary, D. E., White, G. W., Budde, J. F., \& Hoang, Y. V. (2004). Identifying the employment and vocational rehabilitation concerns of people with traditional and emerging disabilities. Journal of Vocational Rehabilitation, 20(1), 71-77.

Nazarov, Z. E., \& von Schrader, S. (2014). Comparison of employer factors in disability and other employment discrimination charges. Rehabilitation Research, Policy, and Education, 28(4), 291-308.

Ozawa, M. N., \& Yeo, Y. H. (2006). Work status and work performance of people with disabilities. Journal of Disability Policy Studies, 17(3), 180-190. doi: 10.1177/10442 073060170030601

Peppas, S. C. (2006). Diversity in the workplace: Hispanic perceptions of the hiring decision. Employee Relations, 28(1/2), 119-129.

Phillips, L. J., \& Stuifbergen, A. K. (2006). Predicting continued employment in persons with multiple sclerosis. Journal of Rehabilitation, 72(1), 35-43.

Pigini, L., Andrich, R., Liverani, G., Bucciarelli, P., \& Occhipinti, E. (2010). Designing reasonable accommodation of the workplace: A new methodology based on risk assessment. Disability and Rehabilitation: Assistive Technology, 5(3), 184-198.

Pranschke, S. C., \& Wright, B. M. (1995). HIV and AIDS-Employers grapple with difficult issues. Benefits Quarterly, 11(3), 41-48.

Ramirez, S. A. (2000). Diversity and the boardroom. Stanford Journal of Law, Business and Finance, 6(1), 85-133.

Rao, D., Angell, B., Lam, C., \& Corrigan, P. (2008). Stigma in the workplace: Employer attitudes about people with HIV in Beijing, Hong Kong, and Chicago. Social Science and Medicine, 67(10), 1541-1549.

Rillotta, F., \& Nettlebeck, T. (2007). Effects of an awareness program on attitudes of students without an intellectual disability towards persons with an intellectual disability. Journal of Intellectual \& Developmental Disability, 32(1), 19-27. doi: 10.1080/13668250701194042

Rioux, M. H., Crawford, C., \& Anweiler, J. (2001). Undue hardship and reasonable accommodation: The view from the court. Policy Studies Journal, 29(4), 641-648.

Salas-Provance, M. B., Erickson, J. G., \& Reed, J. (2002). Disabilities as viewed by four generations of one Hispanic family. American Journal of Speech-Language Pathology, 11(2), 151162. doi: 10.1044/1058-0360

Saunders, J. L., Leahy, M. J., McGlynn, C., \& Estrada-Hernandez, N. (2006). Predictors of employment outcomes for persons with disabilities: An integrative review of potential evidencedbased factors. Journal of Applied Rehabilitation Counseling, 57(2), 3-20.

Schur, L., Kruse, D., \& Blanck, P. (2005). Corporate culture and the employment of persons with disabilities. Behavioral Sciences \& the Law, 23(1), 3-20. doi: 10.1002/bsl.624

Shannon, C. D., Schoen, B., \& Tansey, T. N. (2009). The effect of contact, context, and social power on undergraduate attitudes 
toward persons with disabilities. Journal of Rehabilitation, 75(4), 11-18.

Sherr, M. A., \& Babovich, W. M. (1997). Broadening the scope of the Rehabilitation Act of 1973. Nursing Management, 28(6), 41-42.

Smith, D. L. (2007). The relationship of type of disability and employment status in the United States from the behavioral risk factor surveillance system. Journal of Rehabilitation, 73(2), 32-40.

Unger, D. D. (2002). Employers' attitudes toward persons with disabilities in the workforce: Myths or realities? Focus on Autism and Other Developmental Disabilities, 17(1), 2-10.

Unger, D. D., Jr., Rumrill, P. D., \& Hennessey, M. L. (2005). Resolutions of ADA title I cases involving people who are visually impaired: A comparative analysis. Journal of Visual Impairment and Blindness, 99(8), 453-463.

U.S. Department of Labor (2011). Office of disability employment policy. Retrieved from http://www.dol.gov/odep

Valderrama, H. K. (2010). Is the ADAAA a quick fix or are we out of the frying pan and into the fire? How requiring parties to participate in the interactive process can effect congressional intent under the ADAAA. Houston Law Review, 47(1), 175-214.
Vaughn, M., \& Boston, Q. (2010). Predicting employment outcomes among women of color with psychiatric disabilities. Journal of Vocational Rehabilitation, 33(1), 27-37. doi: 10.3233/JVR-2010-0513

Velcoff, J., Hernandez, B., \& Keys, C. (2010). Employment and vocational rehabilitation experiences of Latinos with disabilities with differing patterns of acculturation. Journal of Vocational Rehabilitation, 33(1), 51-64. doi: 10.3233/JVR2010-0515

Von Schrader, S., Xu, X., \& Bruyère, S. M. (2014). Accommodation requests: Who is asking for what? Rehabilitation Research, Policy, and Education, 28(4), 329-344.

Wolkstein, E., \& Harding, J. (2010). The rehabilitation movement: A resurgence in theory and practice. Journal of Jewish Communal Service, 85(213), 310-319.

World Trade Organization (2015). International trade and market access data. Retrieved from https://www.wto.org/ english/res_e/statis_e/statis_e.htm

Yuker, H. E. (1994). Variables that influence attitudes toward people with disabilities: Conclusions from the data. Psychosocial perspectives on disability [Special issue]. Journal of Social Behavior and Personality, 9(5), 3-22. 